Bruyère , S., VanLooy, S., \& Peterson, D. (2005). The International Classification of Functioning, Disability and Health (ICF): Contemporary literature overview.

Rehabilitation Psychology, 50(2).

(C) 2005 Educational Publishing Foundation.

Originally published in Rehabilitation Psychology, a publication of the American

Psychological Association.

This article may not exactly replicate the final version published in the APA/EPF journal. It is not the copy of record.

\title{
The International Classification of Functioning, Disability and Health: Contemporary Literature Overview
}

\author{
Susanne M. Bruyère \\ Employment and Disability Institute, School of Industrial and Labor Relations, Cornell \\ University \\ Sara A. Van Looy \\ Employment and Disability Institute, School of Industrial and Labor Relations, Cornell \\ University \\ David B. Peterson \\ Institute of Psychology, Illinois Institute of Technology
}

\begin{abstract}
This article reviews the literature from the 3 years since the International Classification of Functioning, Disability and Health's (ICF's) endorsement, focusing on those articles that discuss (a) what the ICF means and how it can be used; (b) the general utility of the ICF for specific fields, such as nursing, occupational therapy, speech-language pathology, and audiology; (c) examples of applications for classification in particular disorders, such as chronic health conditions, neuromusculoskeletal conditions, cognitive disorders, mental disorders, sensory disorders, and primary and secondary conditions in children; (d) uses of the ICF to recode prior work across multiple surveys and across country coding schemes on disability-related national survey items; and (e) governmental uses of the ICF in the United States and selected countries abroad. Future directions needed to effectively implement the ICF across rehabilitation policy, research, and practice are discussed.

This article reviews the literature in psychology and health and human services, and rehabilitation more generally, from the 3 years since the endorsement of the International Classification of Functioning, Disability and Health (ICF). For this review, we narrowed our searches to articles focused on clinical research or specific implementations of the (c) 2005 Educational Publishing Foundation. Used with permission
\end{abstract}


ICF. Most available articles on the ICF discuss its utility for specific groups or particular research areas. The overview of current literature presented here is not exhaustive but rather illustrative of current applications of the ICF to research and practice.

Our review suggests that the actual application of the ICF is as yet somewhat limited because the World Health Organization (WHO) endorsement is so recent; the earliest references using the ICF correspond with the WHO's 2001 endorsement. Standardized application of the ICF in North America has yet to be realized in anticipation of the release of the clinical implementation manual (see Reed et al., 2005); thus, it is not surprising to find limited research on clinical implementation of the ICF. From our review of the literature and of unpublished reports, it seems clear that the ICF is being used in a preliminary fashion to inform conceptual frameworks in research and for recoding data from other health classifications. Recently completed and ongoing research has undoubtedly not yet been published.

In this review, we cluster articles by the following areas: (a) what the ICF means and how it can be used; (b) general utility of the ICF for specific fields, such as nursing, occupational therapy, speech-language pathology, and audiology; (c) examples of applications for classification in particular disorders, such as chronic health conditions, neuromusculoskeletal conditions, cognitive disorders, mental disorders, sensory disorders, and primary and secondary conditions in children; (d) uses of the ICF to recode prior work across multiple surveys and across country coding schemes on disabilityrelated national survey items; and (e) governmental uses of the ICF in the United States and selected countries abroad.

\section{Overview of Literature}

Many articles discuss what the ICF means and its potential use, and this literature presents a variety of supportive perspectives. In a 2003 special issue of Disability and Rehabilitation devoted to the ICF, DeKleijn-de Vrankrijker (2003) offered an overview of the origin of the ICF, beginning with its roots in the International Classification of Impairments, Disabilities and Handicaps (ICIDH; WHO, 1980). Üstün, Chatterji, Bickenbach, Kastanjsek, and Schnieder (2003) outlined the revision process and discussed the rationale for the ICF and the needs that it serves in rehabilitation. Also reviewed in this special issue were some unique features of this classification system, with articles by Perenboom and Chorus (2003) on the Participation measure, and Schneidert, Hurst, Miller, and Üstün (2003) on the Environmental Factor, among others.

Stucki, Ewert, and Cieza (2003) provided a general discussion of the ICF's potential as a functional tool and concluded that the ICF's new language is an exciting landmark for rehabilitation, potentially leading to a stronger position for rehabilitation within the medical community, enhanced multiprofessional communication, and improved communication between patients and rehabilitation professionals. This optimistic view was echoed by Üstün, Chatterji, Bickenbach, et al. (2003), whose overview of the development of the ICF and the needs it serves in rehabilitation led them to conclude that it is a needed and essential tool.

(C) 2005 Educational Publishing Foundation. Used with permission 
Üstün, Chatterji, Kastanjsek, Schnieder, and Bickenbach (2003) suggested that the ICF provides a common framework for describing functional status information in health records to make this information comparable and of value. They stated that the ICF conceptualizes functioning from holistic and lived-experience vantage points, thereby allowing for planning interventions targeted at the whole individual or the environment. They hold that routine collection of functional status information across settings in the health care delivery system can facilitate more effective evaluation of outcomes, comparison of the effectiveness and cost effectiveness of treatment modalities, and prediction and management of costs. Bickenbach, Chatterji, Kastanjsek, and Üstün (2003) discussed the potential utility of the ICF as a framework for evaluating the effects of aging on workers and work environments. Given the increasing global concern for extending working life through a re-visioning of employment and retirement, and the importance of being able to identify and measure age-related functional decrements, the ICF would better enable social policymakers to devise interventions, strategies, and policies that increase work participation.

Although several authors have argued that the ICF holds considerable promise both as a nosological tool and as a heuristic in guiding rehabilitation research, others have expressed reservations and concerns. Nordenfelt (2003) critically analyzed the conceptual platform of the ICF, focusing on the definitions of Activity and Participation. He concluded that these ICF framework areas rest partly on confusion between capacity for action and the actual performance of that action and therefore need to be revised from a conceptual perspective. Imrie (2004) evaluated the theoretical underpinnings of the ICF, arguing that the ICF fails to specify in detail the content of some of its main claims about the nature of impairment and disability, which may limit its educational capacity and influence. Imrie opined that the ICF needs further conceptual clarification and development in several key areas.

Current developments suggest that the disability community supports the conceptualization of disability in the most recent iteration of the ICF (see Hurst, 2003; Threats \& Worrall, 2004). Hurst (2003) traced the thinking about persons with disabilities before and after the formulation of the ICIDH in 1980, including the ICF in its present iteration. She discussed the major shift from the medical model of disability to the interactive model and the effects of Environmental Factors on all aspects of health and functioning. She concluded that proper use of the Environmental Factors within the ICF will foster suitable policies, systems, and services for health care and support; provide measurable indicators for health status and sustainable development; and provide support for the recognition that disability is a human rights issue.

In summary, numerous authors support the ICF framework and its utility for rendering comparable health information from multiple settings, across various applications, and across countries. It also appears to be recognized as a framework that promotes recognition of the role of environmental factors in all aspects of health and functioning. However, several authors point to drawbacks in conceptualization of specific components, which are in need of further study and development. 


\section{Specific Applications to Professions}

This section provides a brief overview of applications of the ICF to specific fields, such as nursing, occupational therapy, speech-language pathology, and audiology. The focus of these articles appears to be one of convincing others in these fields of the utility of the ICF for that discipline.

\section{Nursing}

Kearney and Pryor (2004) reviewed the ICF's relevance as a conceptual framework for nursing, concluding that it has the potential to expand nurses' thinking and practice by increasing awareness of the social, political, and cultural dimensions of disability. These authors held that nursing conceptualizes disability from largely medical and individual perspectives that do not consider its social dimensions and recognized that people with disabilities are critical of this paradigm and its impact on their health care. Arguing that a broader view is necessary, Kearney and Pryor examined the ICF's relation to changing paradigms of disability and presented some applications for nursing. Nursing students could be taught to consider patients as individuals in the context of groups, roles, and environments and given a crucial understanding of the difference between the medical and social models of disability. The authors proposed that the ICF framework might assist the nursing profession to move away from its current focus on impairment and broaden the focus of nursing to include social as well as physical dimensions in the experience of the individual.

In a differing vantage point, Heerkens, VanDerBrug, Ten Napel, and Van Ravensberg (2003) described the use of the ICIDH, the precursor of the ICF, by allied health and nursing professions in the Netherlands. These authors concluded that the level of detail needed for a richer description of the functioning of a patient does not yet exist within the ICIDH or the ICF classification systems.

\section{Occupational Therapy}

Segal, Mandich, Polatajko, and Valiant-Cook (2002) described an application of the ICF in occupational therapy in the United States, a pilot study of stigma and its management, in which ICF codes were used to examine parental perceptions of the experiences of children with developmental coordination disorders. The analysis revealed that the parents believe that their children's impairments restrict their participation in society. The interactions between impairment and participation were interpreted in the context of stigma and its management. Haglund and Henriksson (2003) addressed similarities and differences between concepts in occupational therapy and the ICF. Occupational therapists need an acceptable terminology to describe a client's clinical performance. The language or terminology must be in harmony with common language in the health care system but also reflect occupational therapists' professional responsibility. Two studies were completed in which items in the International Classification of Impairments, Disabilities and Handicaps-Beta-2 draft (ICIDH-2; WHO, 1999) were compared with concepts from the Swedish version of the Assessment of Motor and Process Skills and 
the Assessment of Communication and Interaction Skills. An expert panel of occupational therapists served as raters of clients with learning disabilities and mental health problems. It should be noted that the ICIDH-2 was the last version field tested prior to becoming the ICF; thus, the results of this study likely generalize to the current ICF. Haglund and Henriksson concluded that the ICF is a useful tool for occupational therapists and supported communication between professions but also asserted that it does not replace the professional language of occupational therapists (see Reed et al.'s, 2005, discussion of clinical assessment and the ICF). Further research is indicated to examine how the ICF can be applied in occupational therapy practice.

\section{Speech-Language Pathology}

A number of articles describe efforts to apply the ICF to speech-language pathology. Yaruss and Quesal (2004) compared the ICIDH and ICF frameworks for study of stuttering disorders, with analysis of how the ICF can be adapted to describe the speaker's experience of the disorder. In Canada, Eadie (2003) examined the ICF as a proposed framework for the comprehensive rehabilitation of individuals who use alaryngeal speech. The author provided details about this application (including implications for research and clinical practice in speech pathology) and endorsed the adoption of the framework by the American Speech-Language-Hearing Association (ASHA).

Cruice, Davidson, and Larkins have each used the ICF in doctoral studies (Worrall, 2004). This team has also been collaborating with Travis Threats, who was the ASHA liaison for the revision of the ICIDH-2 and is currently a Senior Consultant and ASHA representative to the American Psychological Association (APA) for development of the North American clinical implementation manual for the ICF (Threats \& Worrall, 2004).

\section{Audiology}

Worrall (2004) described a number of research efforts to evaluate audiology interventions based on the ICF and provided several applications of the ICF framework. Some examples include a project to examine the effectiveness of a participation enablement program for older people in aged care facilities and a current project funded by the National Health and Medical Research Council of the Australian Government to examine the effects of the Active Communication Education Program for older hearing-impaired clients.

In Australian audiology rehabilitation clinics, ICF classifications are used to assist the student audiologist in choosing an assessment and treatment approach that is relevant to the client and uses an approach suitable to the goals of therapy (Worrall, 2004).

\section{Summary}

The literature evidences a significant interest and a variety of efforts to apply the ICF to a number of professional areas, such as nursing, occupational therapy, speech-language pathology, and audiology. In general, the ICF appears to be a useful conceptual 
framework in a particular field and broadens the professionals' thinking. Comments by some authors, however, suggest that the level of detail needed for application in particular professions does not as yet exist nor will it replace the professional language of the specific discipline. In addition, we note that rehabilitation psychology has not as yet yielded significant applications in the published literature, affording many opportunities for future developments.

\section{Specific Applications to Disorders}

The literature summarized to this point largely describes the ICF and its utility or potential utility, but the ICF is clearly coming into use internationally and the literature reflects this. This section considers the ICF as an effective clinical tool with specific disorders, such as chronic health conditions, neuromusculoskeletal conditions, cognitive disorders, mental disorders, sensory disorders, and primary and secondary conditions in children.

\section{Chronic Health Conditions}

Wade and Halligan (2003) characterized the ICF as a useful, but not sufficient, framework for describing the situation of persons with chronic illness. They recounted deficiencies to date in this application of the ICF and suggested including terms that specify normality at the level of organ and person and adding the dimension of time. They concluded that, with revisions, the ICF could be a powerful analytic and explanatory model of human experience and behavior in any situation, not just illness and disease. It is important to note, however, that the ICF was never intended to explain etiology of disease; rather, it was designed to classify functional consequences of health conditions (see Peterson, 2005).

Ewert et al. (2004) identified some common problems in using the ICF checklist with patients with chronic conditions in a multicenter sample of rehabilitation patients who had received a clinical diagnosis of one of 12 chronic conditions. They found that categories from each ICF component were descriptive in most conditions, illustrating the utility of the ICF in classifying functioning and health in patients with chronic conditions.

Weigl et al. (2004) described an effort to identify the most typical and relevant categories of the ICF for patients' chronic conditions. An international expert survey was conducted using the Delphi technique. Answers were then linked to the ICF and analyzed for the degree of consensus. Categories in all ICF components were considered typical and/or relevant by at least four of five responders. All conditions had a distinct typical spectrum of relevant categories, but some common categories were relevant to all the conditions. Weigl et al. concluded that lists of ICF categories relevant and typical to specific conditions could be created - an important step toward identifying ICF core sets for chronic conditions.

\section{Neuromusculoskeletal Conditions}


Rosenbaum and Stewart (2004) promoted the ICF as a model to guide clinical thinking, practice, and research in cerebral palsy, discussing opportunities it provides to look at research questions with a fresh approach. The authors argued that the way we think about health and disease determines to a considerable extent what we do and say in our clinical encounters with patients, and the ICF represents an exciting new way to consider health and disease.

Cieza and Stucki (2004) viewed the ICF as a new global language of functioning and health, with a new perspective for understanding the impact of musculoskeletal conditions. Weigl et al. (2003) linked osteoarthritis-specific health status measures to the ICF, reporting a study to link the Western Ontario and McMaster Universities and Lequesne-Algofunctional indices to the ICF on the basis of rules developed specifically for this purpose. They concluded that the linking process enables the understanding of the relation between health-status measures and the ICF. They saw their results as showing that the ICF classification can become the cardinal reference for existing health-status measures.

Sinnott, Dunn, and Rothwell (2004) reported on an ICF classification application in hand surgery in New Zealand, where the ICF conceptual framework was used to interpret hand function outcomes following tendon transfer surgery for tetraplegia. In this study, the researchers used the ICF to recode results of outcomes at the 10-year rereview and concluded that the ICF enhanced the clinical applicability of the outcome measures.

\section{Cognitive Disorders}

Other authors have explored the ICF's potential for use by rehabilitation professionals working with individuals with cognitive disorders. Arthanat, Nochajski, and Stone (2004) presented information on cognitive disorders, including prevalence, functional manifestations, and the assessment of a person's cognitive functioning, and the applicability of the ICF's holistic classification and coding of cognitive dysfunction within the components of Body Functions and Structures, Activity and Participation, and Environmental Factors. They concluded that the coding system systematically organizes measures related to cognitive status and the resulting functional outcomes. Therefore, the ICF has the potential to classify and interpret cognitive deficits on a global level and thereby reflects on the overall health and functioning of the individual in major life activities. In Austria, Von Wild (2003) described the application of the ICF in neurosurgery in neurorehabilitation clinics, where ICF criteria were used to compare outcomes of different methods of functional neurosurgery. Geyh, Wendel, Heel, and Fries (2002) described how the ICF was applied to a classification of cognitive functions and self-ratings of competency in outpatient neurologic-neuropsychological rehabilitation of patients after acquired brain injury.

Rentsch et al. (2003) discussed the implementation of the ICF in the daily practice of neurorehabilitation at an interdisciplinary project at the Kantonsspital of Lucerne, Switzerland. They found that this ICF classification implementation improved the quality 
of interdisciplinary work processes and contributed to a more systematic approach to rehabilitation tasks by team members.

\section{Mental Disorders}

Kennedy (2003) described the work of the International Mental Health Task Force in the development of all aspects of functioning and disability in the ICF associated with mental disorders. This author also noted several applications of the ICF that are inclusive of the mental health perspective, including the creation of a Procedural Manual and Guide for a Standardized Application of the ICF (see description by Reed et al., 2005) and the future development of the fifth edition of the Diagnostic and Statistical Manual of Mental Disorders.

Kennedy (2002) also described a joint National Institutes of Health-WHO project, funded in 1996 to develop a disability assessment instrument that would be compatible with the evolving ICF. The result is the WHO Disability Assessment Schedule II (WHODAS II; WHO, 2001b), which evolved from work conducted since 1999 in five countries (the United States, Canada, South Africa, Netherlands, and France) to develop methodologies and the related statistical tables to systematically back code to the ICF disability data from selected national disability surveys.

Another activity cited is the use of the conceptual base of the ICF Environmental Factors to formulate the particular aspects of the environment that affect the different activities and life situations of participation for people with mental disorders (Kennedy, 2002). In yet another application related to mental disabilities, Brockow, Wohlfahrt, et al. (2004) used the ICF as a reference in identifying the concepts contained in outcome measures of clinical trials on depressive disorders.

\section{Sensory Disorders}

Moller (2003) highlighted selected strengths and weaknesses of the ICF that were found during a study of people with deaf-blindness; questionnaires and personal interviews were used to examine the application of the ICF framework to this population. These authors found five circumstances that could not be accounted for using the ICF to code survey responses: fast variation in functioning because of different personal and environmental factors, choosing not to do an activity because of a health condition, time loss affecting quality of life, health risks related to particular impairments, and obligations. The authors concluded that the ICF needs further development to address these questions to be useful in the study of deaf-blindness.

Crews and Campbell (2001) used the ICF to analyze data from the National Center for Health Statistics's (NCHS) 1994 Second Supplement on Aging, a follow-up supplement to the 1994 National Health Interview Survey, to examine health conditions, activity limitations, and participation restrictions among older people with visual impairments. Specifically, the authors investigated the health, activity, and social participation of people aged 70 years or older with vision impairment, hearing loss, or both using the ICF 
framework. A hierarchical pattern emerged, as impairments predicted consistent disparities in activities and social participation. The authors used the findings to discuss public health implications for this target group.

\section{Pediatric Rehabilitation}

Several authors have presented illustrations of applications of the ICF to children's disabilities and secondary conditions. Battaglia et al. (2004) described the application of the ICF in a cohort of children with cognitive, motor, and complex disabilities, having studied its correlation with well-established measures of function already in use. They found the ICF to be applicable, reliable, and strongly correlated with established scales. However, they also pointed out that several components do not fully capture the developmental nature of many abilities in children. These authors concluded that the ICF is new and has potential, but experience with its application for children with complex disabilities is still limited.

Simeonsson et al. (2003) discussed the need for a common language and classification of functioning and disability for children. They described the special challenges for classification and measurement presented by the interaction of developmental characteristics and disability among children. They argued that demographic trends emphasize the need for universal measures that encompass the components of the ICF and can be used in surveillance, screening, and evaluation. They concluded that measures should be developed within a framework of children's rights and application of the biopsychosocial model to document profiles of functioning and disability of children.

Simeonsson, McMillen, and Huntington (2002) examined the application of the ICF to secondary conditions in children with spina bifida. The authors reported that the ICF is of value in the study of secondary conditions in the following two ways: (a) as a conceptual framework for defining impairments, activity limitations, and participation restrictions and the mediating role of the environment in their expression and (b) as a taxonomy for coding these dimensions of disability. Simeonsson and associates suggested that the ICF could yield a profile of a child's difficulties and documentation of environmental barriers experienced by that child. Research studies with children and adolescents with spina bifida have revealed that physical and mental impairments and limitations in performing activities and participating in communal life are experienced as secondary conditions, which are preventable. Therefore, identifying the mechanisms associated with their manifestation is an important step toward the development of effective prevention programs.

In the Netherlands, Van Empelen, Jennekens-Schinkel, Buskens, Helders, and Van Nieuwenhuizen (2004) described an ICF classification application to the study of outcomes of surgery for epilepsy in children, specifically looking at the functional consequences of hemispherectomy. In this instance, the ICF was used to code activities and social participation before and after surgery to assess outcomes. 


\section{Summary}

In summary, uses of the ICF as a tool for better classification of health conditions and resulting functional status can be found in an increasing number of clinical areas both within the United States and abroad, ranging across many disability areas and conditions. Authors describing their experiences to date with the ICF generally express enthusiasm about the potential of the ICF as a way to classify the functional consequences of health conditions, to offer a needed new vantage point for counseling and clinical intervention, and to provide a core reference for existing health-status measures.

\section{Comparison With Other Classification Systems}

One future area of development that could lead to more wide-spread use of the ICF is mapping it to items of existing instruments in rehabilitation medicine and other professions (Stucki et al., 2003) to create bridging texts and documents to facilitate dissemination of the ICF. The WHO recently received a NCHS-Centers for Disease Control (CDC) award for a 6-month contract to create crosswalk information from the ICF to a dozen or so major assessment tools (ICF newsletter, September 2004; North American Collaborating Center, 2004). There is a body of work on the ICF that specifically focuses on taking established classification systems and back coding them to the ICF. Reed et al. (2005) addressed the complexities and confounds associated with such endeavors. An example of a conceptual comparative effort between codings of the ICF and other scales is presented in Scherer and Glueckauf's (2005) article, with a focus on dimensions for consideration in the appropriate selection of assistive technology.

Granlund, Eriksson, and Ylven (2004) used the ICF's Activities and Participation dimension in assigning ICF codes to items from existing rating instruments; the focus of the study was the ICF's Participation dimension. Items from extant questionnaires focusing on Participation were assigned to ICF codes on an item-by-item basis in a preliminary investigation of the ICF's theoretical assumption that the Environmental Factors component interacts with the Body Functions and Participation components. The sample comprised students with disabilities, their parents-relatives, their teachersmanagers, and special education consultants. Items from several surveys (the Arc's SelfDetermination Scale, Perceived Interaction Questionnaire, Environments Survey, and The Abilities Index) were used. The study partly confirmed the utility of the ICF Participation dimension in assigning codes to items from extant instruments; moderate statistical correlations between Activities and Participation chapters and between items from different ICF dimensions were found. However, cluster analysis also resulted in groups with Participation patterns not related to type of disability. The authors concluded that this study partly confirmed the utility of the ICF Participation dimension in assigning codes to items from extant instruments but that further analysis and a more extensive questionnaire base are needed.

Wolff et al. (2004) selected studies from Medline between 1993 and 2003, and used the ICF as a reference to identify the concepts contained in outcome measures of clinical trials on four disorders - chronic ischemic heart disease, diabetes mellitus, obesity, and 
obstructive pulmonary disease. Specifically, they extracted outcome measures and concepts contained in outcome measures and linked them to the ICF. These authors found that in all four conditions, the majority of studies were drug trials focusing on clinical parameters and not on functioning. They concluded, however, that the ICF provides a useful reference to identify and quantify the concepts contained in outcome assessment in clinical trials.

Brockow, Cieza, et al. (2004) systematically identified and compared the concepts in outcome measures of clinical trials on low back pain, chronic widespread pain, osteoarthritis, osteoporosis, and rheumatoid arthritis using the ICF as a reference. They selected randomized controlled trials published in Medline between 1991 and 2000 to extract outcome measures and link their concepts to the ICF. One hundred twenty-nine trials on low back pain, 42 trials on chronic widespread pain, 176 trials on osteoarthritis, 107 trials on osteoporosis, and 382 trials on rheumatoid arthritis were included. These researchers concluded that the ICF provides a useful reference to identify and quantify the concepts contained in outcome assessment used in clinical trials.

Swanson, Carrothers, and Mulhorn (2003) described an international effort to use the ICF framework to guide comparisons across disability survey questions in five countries; their process included back coding survey questions to the ICF. To establish a meaningful basis for comparison, they scaled the original 14 functioning areas to seven: hearing, seeing, speaking, mobility, body movement, gripping, and personal care. A rigorous back-coding process resulted in a comprehensive set of survey questions with unique ICF codes. These authors concluded that the question form and focus must be structured to the ICF in the survey development phase to achieve the best possible base for international comparability.

The literature on efforts to compare the ICF to other classification systems provides a number of examples both within the United States and abroad. The resulting literature appears to show that the ICF is as good, or better, at classifying outcomes as the other prior systems have been. Continued work is needed, however, to achieve the desired outcome of using the ICF as a basis for comparability when examining classification systems across countries.

\section{ICF Governmental Uses}

Kennedy (2002) offered an overview of U.S. federal government activities related to the ICF across agencies. The National Committee on Vital and Health Statistics submitted a report to Department of Health and Human Services (DHHS) Secretary Tommy Thompson surveying current and potential uses of the ICF and recommending it be studied for use as a reporting tool for functional status. The U.S. Office of Personnel Management has been revising the form that federal government employees use to voluntarily identify themselves as having a disability, using the ICF Checklist of Major Activities. In a related activity in the U.S. federal government, the DHHS reviewed existing national surveys, and items pertaining to disability factors related to functioning were coded and organized using the ICF classification system. Eleven federal surveys or 
data sets were reviewed in this way (e.g., the National Health Interview SurveyDisability Supplement and the Survey of Income and Program Participation). It was concluded that the resulting draft compendium has potential utility but that for enhanced usefulness, additional work is needed to assure that it is formatted for audiences of researchers, survey designers, and data and policy analysts.

Madden, Choi, and Sykes (2003) described an introduction of the ICF into Australian data dictionaries and its use as a framework to inform and structure questions in the Australian National Disability Survey. The authors also briefly described the University of Queensland Communication Disability in Ageing Research Unity effort in using the ICF in education of speech pathologists and audiologists, in clinical practice with older people with hearing impairment and aphasia, and predominantly as a research tool.

Additional European uses of the ICF in the Netherlands and France can be identified. Savel, Autry, and Lollar (2004) described work in the Netherlands to integrate disability and functional status data into the national public health information architecture. The researchers defined modifications needed for integration of the ICF conceptual models into the National Electronic Disease Surveillance System and concluded that with only a few modifications, the ICF conceptual models could be integrated into the Dutch public health system.

The Dutch are also implementing the ICF in their activities to promote a physically active lifestyle for individuals with disabilities, with an ICF-based model for studying physical activity behaviors currently used in 10 Dutch rehabilitation centers (Van der Ploeg, Van der Beek, Van der Woude, \& Van Mechelen, 2004). Caulfield, Saleeby, and Placek (2003) reported that in France there are a number of initiatives at both the local and national levels using the ICF in training, surveys, studies, and assessments. The ICF is being used as a model in a current reform of legislation for people with disabilities.

Mbogoni (2003) reviewed the application of the ICIDH and the ICF in developing countries using data and information available in the United Nations Disability Statistics Database at the United Nations Statistics Division; this effort included studies carried out in the 1990s and the 2000 round of censuses. The author found that, for the most part, in past surveys ICIDH-ICF definitions were not used internationally in constructing census questions on disability but that more recent surveys were beginning to show use of ICIDH-ICF classification structures. Mbogoni concluded that the work of the United Nations Statistics Division aimed at improving the international comparability of methods and of use of international standards could increase adoption of the ICF in disability measurement in the future.

There are a number of efforts internationally to date on governmental uses of the ICF, most of these in developed countries. It appears that future efforts in developing countries are possible if the ICF can be introduced early on in the development of individual countries' national surveys that include health and disability questions. 


\section{Implications and Future Directions}

An overview of the literature affirms that the ICF and its conceptual framework have increasingly influenced governmental, health care, and rehabilitation entities both in the United States and abroad. For a review of proposed future uses of the ICF, the reader is referred to Stucki et al. (2003) and to Reed et al. (2005). Here, we briefly discuss the implications of these findings and provide recommendations for needed future directions, specifically with a focus on research and clinical applications.

\section{Research}

The ICF is now used in several countries besides the United States, including Australia, Canada, and the Netherlands (Bickenbach, 2003; Holloway, 2004). Canada adopted the ICF through the Canadian Institute for Health Information, and the Australian Institute of Health and Welfare has applied the ICF to their national data dictionaries (Madden et al., 2003). In addition, work based on the ICF conceptual framework is currently underway within the World Health Survey and has been implemented in 74 countries (Üstün, Chatterji, Bickenbach, Kastanjsek, \& Schnieder, 2003). These projects provide increasing opportunities for research both in the United States and abroad.

Research using the concepts and framework of the ICF, as well as implementation of the ICF itself, shows great promise in improving the quality of health care services for individuals across the world, generating innovative outcome-based research and proactively influencing culturally sensitive global health policy (Stucki et al., 2003). The ICF can be used in rehabilitation psychology research as a standard for defining concepts, hypothesizing relationships, building constructs, and proposing new theories that can further research and practice well into the 21st century (WHO, 2001a).

Research associated with the development of the ICIDH does not necessarily generalize to the ICF as it is currently constructed, given the significant changes to the classification system, such as the collapsing of the Activity and Participation components into one unified listing. Extensive field testing of the ICF is needed, along with the establishment of regional and international normative data. Our review of the literature validates that the model of disability and functioning proposed requires further study. Data need to be collected on the various constructs presented, associations need further exploration, and causal links need to be hypothesized and validated.

Although the ICF was adopted as the complement to the International Statistical Classification of Diseases and Related Health Problems, Tenth Revision (WHO, 1992), the 191 member states who were encouraged to use it initially did not have the extensive resources needed to implement the ICF. These constraints may be eventually overcome, as international efforts to use the ICF in research and practice are ever increasing. Within the United States, the National Institute on Disability and Rehabilitation Research, the 
$\mathrm{NIH}$, and the CDC have directed funding to research that uses the ICF and its conceptual framework.

\section{Clinical Implementation}

Our review of the literature affirms that the ICF is increasingly affecting the practice of particular professionals and clinical interventions more broadly. For example, the ICF framework has had a direct impact on the scope of practice statement for the speechlanguage pathology profession (ASHA, 2001; Threats, 2003; Threats \& Worrall, 2004) and has influenced activities related to data collection, framing assessment interventions, measuring clinical research outcomes (Threats, 2002), and research investigating the role of communication in the quality of life (Threats \& Worrall, 2004).

Specifically relevant to psychology, to help implement the ICF in clinical settings, the APA and the WHO formed an interdisciplinary team of experts to develop the Procedural Manual and Guide for a Standardized Application of the ICF: A Manual for Health Professionals. The completed manual is anticipated to be a joint publication of the APA and the WHO, appearing sometime in 2005 (Holloway, 2004; Threats \& Worrall, 2004; see Reed et al., 2005, for a review of subsequent developments). A prototype manual for four chapters from the ICF has been disseminated for field testing (Holloway, 2004).

A manual that associates the ICF with contemporary assessment practices would assist novice classification users to orient to the ICF and apply it to research and practice. The joint APA-WHO project, along with Australia's version of a similar manual, are positive developments toward this end. However, the creation of a clinical implementation manual adds another layer of complexity to ICF implementation. Once completed, APA and WHO will need to assess clarity and utility of their implementation manual and ultimately the impact of the manual on application of the ICF to clinical practice. Researchers will need to compare these data with other country's efforts like those of Australia. Ideally, the manual will help with interpretation of the codes themselves and standardize the application of qualifiers like Capacity and Performance. Complementary training will also need to be developed to facilitate consistent coding guidelines from the WHO and its collaborating centers. Regional and international systems need to be created for incorporating feedback from the users of future iterations of the ICF. Throughout, those involved with clinical implementation will have the challenge of balancing the establishment of useful standards with maintaining a broad enough application of the ICF to preserve its full utility.

Reed et al. (2005) provided an exciting update on progress toward clinical implementation of the ICF in North America and predicted a significant impact of the ICF on world health care service delivery. These events strongly suggest that health care providers, especially rehabilitation psychologists, should become familiar with applying this classification scheme in their clinical and research practice and also remain current with relevant future developments in this classification system. 
Different professions over time will use specific codes more frequently than others and assemble compendia of information relevant to their specific areas of practice. For example, rehabilitation psychologists may use chapters addressing mental functions, structures of the nervous system, and learning and applying knowledge, whereas physiatrists might spend more time with chapters addressing neuromusculoskeletal and movement-related functions, structures related to movement, and mobility. Rehabilitation psychologists' focus on a broad spectrum of disabling conditions may, in fact, make many aspects of the ICF useful in assessment and treatment planning. ICF core sets of items can be constructed for specific areas within rehabilitation (e.g., stroke, spinal cord injury, traumatic brain injury) to limit coder burden (Stucki et al., 2003; Threats \& Worrall, 2004).

\section{Conclusions}

The results of our review of the literature are encouraging. In these very early stages of the ICF implementation, there have been a significant number of efforts both in the United States and abroad to examine the conceptual utility of this classification framework for the fields of rehabilitation, health, and other clinical practices. In addition, serious work has begun to examine how this classification system relates to specific national and international surveys where measures relevant to the interests of people with disabilities are reflected.

Finally, applications in a wide variety of clinical and research settings are occurring, exploring how the ICF can be used to classify and measure the wide variety of behaviors and indices that fully reflect the whole individual and his or her environment. Although ongoing work is needed to prove and support the utility of the ICF, these uses reflect the philosophical and conceptual intent of the ICF and send a resounding message that although very much in its infant stages, its original intent is incrementally being realized with the promise of full realization in the future.

\section{References}

American Speech-Language-Hearing Association (2001). Scope of practice for speech language pathology. Rockville, MD: Author.

Arthanat, S., Nochajski, S., \& Stone, J. (2004). The international classification of functioning, disability and health and its application to cognitive disorders. Disability and Rehabilitation, 26, 235-245.

Battaglia, M., Russo, E., Bolla, A., Chiuuso, A., Bertelli, S., Pellegri, A. et al. (2004). International classification of functioning, disability and health in a cohort of children with cognitive, motor, and complex disabilities. Developmental Medicine and Child Neurology, 46, 98-106. 
Bickenbach, J. E. (2003). Functional status and health information in Canada: Proposals and prospects. Health Care Financing Review, 24, 89-102.

Bickenbach, J. E., Chatterji, S., Kastanjsek, N., \& Üstün, B. (2003). Ageing, disability and the WHO's international classification of functioning, disability and health (ICF). The Geneva Papers on Risk and Insurance, 28, 294-303.

Brockow, T., Cieza, A., Kuhlow, H., Sigl, T., Franke, T., Harder, M., \& Stucki, G. (2004). Identifying the concepts contained in outcome measures of clinical trials on musculoskeletal disorders and chronic widespread pain using the international classification of functioning, disability and health as a reference. Journal of Rehabilitation Medicine, 44, 30-36.

Brockow, T., Wohlfahrt, K., Hillert, A., Geyh, S., Weigl, M., Franke, T. et al. (2004). Identifying the concepts contained in outcome measures of clinical trials on depressive disorders using the ICF as a reference. Journal of Rehabilitation Medicine, 44, 49-55.

Caulfield, D., Saleeby, P., \& Placek, P. (2003, October). Report of the ninth annual North American Collaborating Center conference on ICF. Paper presented at the meeting of the World Health Organization Collaborating Centres for the Family of International Classifications, Cologne, Germany.

Cieza, A., \& Stucki, G. (2004). New approaches to understand the impact of musculoskeletal conditions. Best Practice and Research: Clinical Rheumatology, 18, 141-154.

Crews, J., \& Campbell, V. (2001). Health conditions, activity limitations, and participation restrictions among older people with visual impairments. Journal of Visual Impairments and Blindness, 95, 453-467.

DeKleijn-de Vrankrijker, M. (2003). The long way from the international classification of impairments, disabilities and handicaps (ICIDH) to the international classification of functioning, disability and health (ICF). Disability and Rehabilitation, 25, 561-564.

Eadie, T. (2003). The ICF: A proposed framework for comprehensive rehabilitation of individuals who use alaryngeal speech. American Journal of Speech-Language Pathology, 12, 189-197.

Ewert, T., Fuessl, M., Cieza, A., Andersen, C., Chatterji, S., Kastanjsek, N., \& Stucki, G. (2004). Identification of the most common patient problems in patients with chronic conditions using the ICF checklist. Journal of Rehabilitation Medicine, 44, 2229. 
Geyh, S., Wendel, C., Heel, S., \& Fries, W. (2002). Cognitive functions and self-rating of competency in outpatient neurological-neuropsychological rehabilitation. Zeitscrhiftfuer-Neuropsychologie, 13, 281-289.

Granlund, M., Eriksson, L., \& Ylven, R. (2004). Utility of international classification of functioning, disability and health's participation dimension in assigning ICF codes to items from extant rating instruments. Journal of Rehabilitation Medicine, 36, 130-137.

Haglund, L., \& Henriksson, C. (2003). Concepts in occupational therapy in relation to the ICF. Occupational Therapy International, 10, 253-268.

Heerkens, Y., VanDerBrug, Y., Ten Napel, H., \& Van Ravensberg, D. (2003). Past and future use of the ICF (former ICIDH) by nursing and allied health professionals.

Disability and Rehabilitation, 25, 620-627.

Holloway, J. D. (2004, January). A new way of looking at health status. Monitor on Psychology, 35, 32.

Hurst, R. (2003). The international disability rights movement and the ICF. Disability and Rehabilitation, 25, 572-576.

Imrie, R. (2004). Demystifying disability: A review of the international classification of functioning, disability and health. Sociology of Health and Illness, 26, 287-305.

Kearney, P., \& Pryor, J. (2004). The international classification of functioning, disability and health and nursing. Journal of Advanced Nursing, 46, 162-170.

Kennedy, C. (2002, November). Federal activities related to the World Health Organization's international classification of functioning, disability and health (ICF). Retrieved November 19, 2004, from http://www.cdc.gov/nchs/data/icd9/agencyuseICF.pdf

Kennedy, C. (2003). Functioning and disability associated with mental disorders: The evolution since ICIDH. Disability and Rehabilitation, 25, 611-619.

Madden, R., Choi, C., \& Sykes, C. (2003). The ICF as a framework for national data: The introduction of ICF into Australian data dictionaries. Disability and Rehabilitation, 25, 676-682.

Mbogoni, M. (2003). On the application of the ICIDH and ICF in developing countries: Evidence from the United Nations Disability Statistics Database (DISTAT). Disability and Rehabilitation, 25, 644-658.

Moller, K. (2003). Deafblindness: A challenge for assessment. Is the ICF a useful tool? International Journal of Audiology, 42, S140-S142. (Suppl. 1) 
Nordenfelt, L. (2003). Action theory, disability, and ICF. Disability and Rehabilitation, 25, 1075-1079.

North American Collaborating Center (2004). NACC clearinghouse on ICF-September 2004 messages. Retrieved March 15, 2005, from http://www.cdc.gov/nchs/data/icd9/icfsept04.pdf

Perenboom, R., \& Chorus, A. (2003). Measuring participation according to the international classification of functioning, disability and health (ICF). Disability and Rehabilitation, 25, 577-587.

Peterson, D. B. (2005). International classification of functioning, disability and health: An introduction for rehabilitation psychologists. Rehabilitation Psychology, 50, 105-112.

Reed, G. M., Lux, J. B., Bufka, L. F., Trask, C., Peterson, D. B., Stark, S. et al. (2005). Operationalizing the international classification of functioning, disability and health in clinical settings. Rehabilitation Psychology, 50, 122-131.

Rentsch, H., Bucher, P., Dommen Nyffeler, I., Wolf, C., Hefti, H., Fluri, E. et al. (2003). The implementation of the international classification of functioning, disability and health (ICF) in daily practice of neurorehabilitation: An interdisciplinary projected at the Kantonsspital of Lucerne, Switzerland. Disability and Rehabilitation, 25, 411-421.

Rosenbaum, P., \& Stewart, D. (2004). The World Health Organization international classification of functioning, disability and health: A model to guide clinical thinking, practice, and research in the field of cerebral palsy. Seminars in Pediatric Neurology, 11, 5-10.

Savel, T., Autry, A., \& Lollar, D. (2004). The National Electronic Disease Surveillance System (NEDSS) and the international classification of functioning, disability and health (ICF): Integrating disability and functional status data into the national public health information architecture. In. M. Fieschi, E. Coiera, \& Y.-C. J. Li (Eds.), Medinfo 2004; Proceedings of the 11th World Congress on Medical Informatics (CD-ROM ed.). Amsterdam: IOS Press.

Scherer, M. J., \& Glueckauf, R. (2005). Assessing the benefits of assistive technologies for activities and participation. Rehabilitation Psychology, 50, 132-141.

Schneidert, M., Hurst, R., Miller, J., \& Üstün, T. B. (2003). The role of environment in the international classification of functioning, disability and health (ICF). Disability and Rehabilitation, 25, 588-595.

Segal, R., Mandich, A., Polatajko, H., \& Valiant-Cook, J. (2002). Stigma and its management: A pilot study of parental perceptions of the experiences of children with 
developmental coordination disorder. American Journal of Occupational Therapy, 56, 422-428.

Simeonsson, R., Leonardi, M., Lollar, D., Bjorck-Akesson, E., Hollenweger, J., \& Martinuzzi, A. (2003). Applying the international classification of functioning, disability and health (ICF) to measure childhood disability. Disability and Rehabilitation: An International Multidisciplinary Journal, 25, 602-610.

Simeonsson, R., McMillen, J., \& Huntington, G. (2002). Secondary conditions in children with disabilities: Spina bifida as a case example. Mental Retardation and Developmental Disabilities Research Reviews, 8, 198-205.

Sinnott, K., Dunn, J., \& Rothwell, A. (2004). Use of the ICF conceptual framework to interpret hand function outcomes following tendon transfer surgery for tetraplegia. Spinal Cord, 42, 396-400.

Stucki, G., Ewert, T., \& Cieza, A. (2003). Value and application of the ICF in rehabilitation medicine. Disability and Rehabilitation, 25, 628-634.

Swanson, G., Carrothers, L., \& Mulhorn, K. (2003). Comparing disability survey questions in five countries: A study using ICF to guide comparisons. Disability and Rehabilitation: An International Multidisciplinary Journal, 25, 665-675.

Threats, T. (2002). Evidence based practice research using the WHO framework. Journal of Medical Speech-Language Pathology, 10, xvii-xxiv.

Threats, T. (2003, January 7). The framework for ASHA's revised scope of practice in speech-language pathology. Retrieved June 6, 2003, from http://www.speechpathology.com/articles/arc_disp.asp?id=8

Threats, T. T., \& Worrall, L. (2004). Classifying communication disability using the ICF. Advances in Speech Language Pathology, 6, 53-62.

Üstün, T., Chatterji, S., Bickenbach, J., Kastanjsek, N., \& Schnieder, M. (2003). The international classification of function, disability and health: A new tool for understanding disability and health. Disability and Rehabilitation: An International Multidisciplinary Journal, 25, 565-571.

Üstün, T., Chatterji, S., Kastanjsek, N., Schnieder, M., \& Bickenbach, J. (2003). WHO's ICF and functional status information in health records. Health Care Financing Review, 24, 77-88.

Van der Ploeg, H., Van der Beek, A., Van der Woude, L., \& Van Mechelen, W. (2004). Physical activity for people with a disability: A conceptual model. Sports Medicine, 34, 639-649. 
Van Empelen, R., Jennekens-Schinkel, A., Buskens, E., Helders, P., \& Van Nieuwenhuizen, O. (2004). Functional consequences of hemispherectomy. Brain, 127, 2071-2079.

Von Wild, K. (2003). New development of functional neurorehabilitaiton in neurosurgery. Acta Neurochirurgica, 87, 43-47.

Wade, D., \& Halligan, P. (2003). New wine in old bottles; The WHO ICF as an explanatory model of human behavior. Clinical Rehabilitation, 17, 349-354.

Weigl, M., Cieza, A., Andersen, C., Kollerits, B., Amann, E., \& Stucki, G. (2004). Identification of relevant ICF categories in patients with chronic health conditions: A Delphi exercise. Journal of Rehabilitation Medicine, 44, 12-21.

Weigl, M., Cieza, A., Harder, M., Geyh, S., Amanna, E., Kastanjsek, N., \& Stucki, G. (2003). Linking osteoarthritis-specific health status measures to the international classification of functioning, disability and health (ICF). Osteoarthritis and Cartilage, 11, 519-523.

Wolff, B., Cieza, A., Parentin, A., Rauch, A., Sigl, T., Brockow, T., \& Stucki, A. (2004). Identifying the concepts contained in outcome measures of clinical trials on four internal disorders using the international classification of functioning, disability and health as a reference. Journal of Rehabilitation Medicine, 44, 37-42.

World Health Organization (1980). International classification of impairments, disabilities, and handicaps (ICIDH). Geneva, Switzerland: Author.

World Health Organization (1992). International statistical classification of diseases and related health problems, tenth revision (ICD-10). Geneva, Switzerland: Author.

World Health Organization (1999). ICIDH-2: International classification system of functioning and disability—Beta-2 draft, short version. Geneva, Switzerland: Author.

World Health Organization (2001a). International classification of functioning, disability and health (ICF). Geneva, Switzerland: Author.

World Health Organization (2001b). World Health Organization Disability Assessment Schedule II (WHODAS II). Retrieved March 15, 2005, from http://www.who.int/lcidh/whodas/index.html

Worrall, L. (2004). ICF Australian user guide V. 1.0: ICF applications-Examples. Retrieved October 14, 2004, from http://www.aihw.gov.au/publications/dis/icfaugv1/ug_s10_5.html 
Yaruss, J., \& Quesal, R. (2004). Stuttering and the international classification of functioning, disability and health: An update. Journal of Communication Disorders, 37, 35-52.

The research described in this article was made possible through U.S. Department of Education National Institute on Disability and Rehabilitation Research Grant H133B980038 to Cornell University for a Rehabilitation Research and Training Center for Economic Research on Employment Policy for People With Disabilities. We would like to acknowledge the editorial assistance of Robert Glueckauf, Geoffrey Reed, and Andrew Houtenville in the preparation of this article.

Correspondence concerning this article should be addressed to Susanne M. Bruyère, Employment and Disability Institute, School of Industrial and Labor Relations, Cornell University201K ILR Extension Building, Ithaca, NY 14853-3901

E-mail: smb23@cornell.edu 